CARDIOVASCULAR MEDICINE

\title{
Poor concordance of commonly used echocardiographic measures of left ventricular diastolic function in patients with suspected heart failure but preserved systolic function: is there a reliable echocardiographic measure of diastolic dysfunction?
}

\author{
M C Petrie, K Hogg, L Caruana, J J V McMurray
}

Heart 2004;90:511-517. doi: 10.1136/hrt.2003.011403

See end of article for authors' affiliations

Correspondence to: Professor J J V McMurray, Department of Cardiology, Western Infirmary Glasgow G12 8QQ, UK; j.mcmurray@bio.gla.ac.uk

Accepted

2 September 2003
Objective: To determine the concordance of different Doppler echocardiographic criteria for "diastolic dysfunction" in patients with suspected heart failure but preserved left ventricular systolic function.

Design: Prospective, descriptive study.

Setting: Outpatient based direct access echocardiography service.

Patients: Consecutive patients referred with suspected heart failure but preserved left ventricular systolic function.

Measurements: Echocardiographic measurements of systolic and diastolic function. Eight published studies giving age and sex specific ranges for measures of diastolic function in healthy subjects were reviewed and the proportion of patients outside the normal limits for each of these published ranges was calculated.

Results: There was very poor concordance between measures with up to a 16-fold difference in the prevalence of diastolic dysfunction in the overall patient cohort. Even for a given measure, there was relatively poor agreement between the published reference ranges. In subsets likely to include patients at high risk of having diastolic dysfunction, an increased prevalence of diastolic dysfunction was not evident with any measure in any patient subset.

Conclusions: Our findings challenge the use of the diagnosis of diastolic heart failure based on the most commonly used echocardiographic criteria. Physicians should be cautious about echocardiographic reports describing diastolic dysfunction and only apply the diagnosis of diastolic heart failure with great care.
$\mathrm{T}$ here has been tremendous recent interest in the concept of "diastolic dysfunction" as a cause of heart failure. ${ }^{12}$ To a great extent this has been fuelled by the finding that many patients with a clinical diagnosis of heart failure have preserved left ventricular systolic function..$^{3-7}$ Diastolic dysfunction is, therefore, frequently proposed as the underlying problem in these patients. This view has been further popularised by the widespread availability of Doppler echocardiography. There are relatively simple measurements that can be made with this technique and that have been advocated (and readily accepted) as indices of diastolic function. ${ }^{128-13}$ The concordance and, indeed, validity of these indices are relatively poorly documented in humans. Yet, commonly, breathless patients with suspected heart failure are referred for an echocardiogram, which is routinely reported as showing normal systolic function but evidence of diastolic dysfunction. We have taken the most commonly advocated echocardiographic criteria for diastolic function and applied these different measures to a cohort of patients with suspected heart failure referred for transthoracic echocardiography. Our aim was to determine the concordance of different diagnostic criteria for diastolic dysfunction.

\section{METHODS}

\section{Patients}

The cohort of patients studied was one referred by general practitioners to a direct access echocardiography service provided by the department of cardiology at the Western Infirmary, Glasgow. Referrals were invited for patients thought to have heart failure and for whom the initiation of an angiotensin converting enzyme inhibitor was being considered. The focus of this analysis was patients with preserved left ventricular systolic function. Patients with left ventricular systolic dysfunction (according to qualitative "eyeball" assessment; see below), significant valvar heart disease, and atrial fibrillation were not studied further. The study was approved by our local committee for medical ethics. Each patient gave written informed consent.

\section{Transthoracic echocardiography}

All examinations were performed by a single operator (LC) on an Acuson $128 \times \mathrm{P} 10 \mathrm{c}$ (Acuson, Berkshire, UK), as previously described. ${ }^{14}{ }^{15}$ With the patient resting in the left lateral decubitus position $\mathrm{M}$ mode, two dimensional, and Doppler ultrasound examinations were carried out.

Left ventricular systolic function was assessed qualitatively by the "eyeball" technique from two dimensional images ${ }^{16}{ }^{17}$ and quantitatively by measurement of ejection fraction and fractional shortening with $M$ mode echocardiography.

Abbreviations: A, peak atrial filling; $E$, peak rapid filling; IVRT, isovolumetric relaxation time 
Ejection fraction was also measured with the Simpson's biplane method.

Pulsed wave Doppler measurements were made at the tips of the mitral valve leaflets in the apical four chamber view. Early diastolic flow (E wave) and atrial contraction (A wave) were measured at the peak velocity. Deceleration time was measured from the peak of the $\mathrm{E}$ wave to the point of interception of the baseline. The area under the curve was measured for both E and A waves, representing peak rapid filling and peak atrial filling, respectively. These measurements were then used to estimate the atrial filling fraction, where atrial filling fraction is determined by A / A + E.

The pulsed Doppler sample was then positioned midway between the mitral valve tips and the aortic outflow track so that isovolumetric relaxation time (IVRT) could be measured between the point of aortic valve closure and mitral valve opening. All of the above measurements were repeated six times and their means calculated for a statistical analysis.

\section{Reference ranges for measures of diastolic function}

We conducted an electronic literature search (and a manual search of textbooks) for studies giving age and sex specific ranges for conventional Doppler measures of diastolic function in healthy people. We identified eight studies describing more than 30 subjects. ${ }^{9}{ }^{18-24}$ These studies included between 32 and 980 unselected participants from the general population. Five had more than 100 participants and seven had more than 80. From the ranges provided, an upper and lower limit of normal was calculated as two standard deviations above or below the normal range reported (appendix 1). The recently published criteria of the European Study Group on Diastolic Heart Failure were also used. ${ }^{11}$

\section{Proportions of patients with diastolic dysfunction}

We then calculated the proportion of our patients who were outside the normal limits for each of the published ranges ${ }^{918-24}$ and those advocated by the European Study Group on Diastolic Heart Failure. ${ }^{11}$ To explore further the value of these measures, we also examined the proportions of measurements that lay outside these normal ranges in four subsets of patients at higher risk of diastolic dysfunction. The subsets were patients with hypertension (defined as a recorded clinical history of hypertension), left ventricular hypertrophy (defined as a septal or posterior wall measurement $>1.1 \mathrm{~cm}$ on $\mathrm{M}$ mode echocardiography), obesity (defined as a body mass index of $>30.0$ ), and myocardial ischaemia (defined as a history of angina, myocardial infarction, coronary artery bypass grafting, or electrocardiographic changes consistent with a diagnosis of coronary heart disease). Electrocardiographic changes consistent with a diagnosis of coronary heart disease were pathological Q waves, left bundle branch block, and ST segment or $\mathrm{T}$ wave abnormalities in $\geqslant 2$ consecutive leads.

\section{RESULTS}

\section{Patients}

One hundred and forty seven patients with suspected heart failure were referred. Twenty two patients had left ventricular systolic dysfunction. Ten patients had atrial fibrillation alone, two patients had valvar disease alone, and four patients had both atrial fibrillation and valvar heart disease. One hundred and nine patients had suspected heart failure in the absence of left ventricular systolic function, valvar heart disease, or atrial fibrillation. Table 1 summarises characteristics of these 109 patients.

\section{Concordance between different measures of diastolic function}

Tables 2 and 3 show the proportion of patients in our study who were more than two standard deviations outside the
Table 1 Patient characteristics and medication

\begin{tabular}{ll} 
& $\begin{array}{l}\text { Mean (SD) or } \\
\text { number }\end{array}$ \\
\hline Patient characteristics ( $\mathrm{n}=109)$ & $71(11)$ \\
Age (years) & $34 / 75$ \\
Sex (male/female) & $152(23)$ \\
Systolic BP (mm Hg) & $85(11)$ \\
Diastolic BP (mm Hg) & $74(16)$ \\
Heart rate (beats/min) & $30(7)$ \\
Fractional shortening (\%) & $56(11)$ \\
Ejection fraction (M mode) (\%) & $45(10)$ \\
Ejection fraction (Simpson's biplane) (\%) & 51 \\
Hypertension & 12 \\
Myocardial infarction & 7 \\
Coronary artery bypass grafting & 25 \\
Pulmonary disease & \\
Medication & 85 \\
Diuretics & 18 \\
$\beta$ Blockers & 22 \\
Nitrates & 22 \\
Calcium channel blockers & 6 \\
ACE inhibitors & 33 \\
Aspirin & 22 \\
Inhaled $\beta_{2}$ agonists & 8 \\
Inhaled corticosteroids & 6 \\
Oral hypoglycaemic agents & 3 \\
Lipid lowering agents & 9 \\
Non-steroidal anti-inflammatory agents & 4 \\
Digoxin & 2 \\
Warfarin & \\
\hline ACE, angiotensin converting enzyme; BP, blood pressure. \\
\end{tabular}

published normal ranges for each of the measures of diastolic function used in the individual reference studies. The purpose of these tables is to illustrate the level of concordance between the different measures of diastolic available within the published reference studies.

As can be seen, there was considerable disagreement between measures. For example, based on the data published by Mantero and colleagues, ${ }^{18}$ there was a fourfold difference in the prevalence of diastolic dysfunction in the age group 40-49 years, depending on which measure was used (table 3). The proportions varied fivefold and sixfold in the age ranges 50-59 and 60-69 years. In the age group 70-79 years there was a 10-fold difference, with a prevalence of diastolic dysfunction of $4 \%$ if the E:A ratio was used versus 39\% if an abnormal IVRT was used.

The other reference studies show much the same pattern, with IVRT and deceleration time giving much higher proportions of abnormal results than the other measures. $\mathrm{E}: \mathrm{A}$ ratio generally gave the lowest prevalence of diastolic dysfunction. The data derived from the reference range of Spirito and colleagues ${ }^{19}$ gave another striking example of the discrepancy between prevalence based on E:A ratio and prevalence based on IVRT. For the age range 50-74 years the prevalence of diastolic dysfunction in our patients is $2 \%$ with E:A ratio and $35 \%$ based on IVRT.

Indeed, even for a given measure, there was relatively poor agreement between the published reference ranges (and, therefore, the proportion outside those ranges). For example, the Framingham study ${ }^{20}$ reference range for E:A ratio led to a diagnosis of diastolic dysfunction in 1 of 19 (5.3\%) of our patients aged 60-69 years, whereas the reference range of Mantero and colleagues ${ }^{18}$ for E:A ratio led to this diagnosis in 4 of 19 (21\%) of our patients (table 2 ). For patients aged 40-60 years similar large discrepancies between these two studies were apparent when using atrial filling fraction-that is, 10 of $13(77 \%)$ with the Framingham range versus 0 of $13(0 \%)$ with that of Mantero and colleagues. ${ }^{18}$ 
Table 2 Concordance between the prevalence of diastolic dysfunction using different published reference ranges for individual echocardiographic measures

\begin{tabular}{|c|c|c|c|c|c|}
\hline \multirow[b]{3}{*}{ Age range (years) } & \multicolumn{5}{|l|}{ E:A ratio* } \\
\hline & \multirow[b]{2}{*}{ Framingham study ${ }^{20}$} & \multirow[b]{2}{*}{ Mantero et $a l^{18}$} & \multirow[b]{2}{*}{ Klein ef $a R^{4}$} & \multicolumn{2}{|c|}{ Cardiovascular health study ${ }^{22}$} \\
\hline & & & & Men & Women \\
\hline $\begin{array}{l}40-49 \\
50-59 \\
60-69 \\
70-79 \\
\geqslant 70 \\
>80\end{array}$ & $\begin{array}{l}1 / 5 \\
1 / 8 \\
1 / 19 \\
\text { NA } \\
2 / 64 \\
\text { NA }\end{array}$ & $\begin{array}{l}1 / 5 \\
0 / 8 \\
4 / 19 \\
2 / 47 \ddagger \\
\text { NA } \\
\text { NA }\end{array}$ & $\begin{array}{l}1 / 5 \\
3 / 8 \\
4 / 19 \\
\text { NA } \\
2 / 64 \S \\
\text { NA }\end{array}$ & $\begin{array}{l}\text { NA } \\
\text { NA } \\
1 / 5 \dagger \\
0 / 11 \\
\text { NA } \\
3 / 4\end{array}$ & $\begin{array}{l}\text { NA } \\
\text { NA } \\
0 / 7 \dagger \\
4 / 34 \\
\text { NA } \\
5 / 15\end{array}$ \\
\hline & \multicolumn{2}{|l|}{ IVRT } & & & \\
\hline & Mantero et a $\left.\right|^{18}$ & Klein et $a P^{4}$ & & & \\
\hline $\begin{array}{l}40-49 \\
50-59 \\
60-69 \\
70-79 \\
>70\end{array}$ & $\begin{array}{l}4 / 5 \\
5 / 8 \\
4 / 20 \\
20 / 51 \S \\
\text { NA }\end{array}$ & $\begin{array}{l}3 / 5 \\
0 / 8 \\
0 / 20 \\
\text { NA } \\
27 / 67\end{array}$ & & & \\
\hline & \multicolumn{3}{|l|}{ AfF } & & \\
\hline & Framingham study ${ }^{20}$ & Mantero et $a l^{18}$ & Voutilainen ef $a P^{1}$ & & \\
\hline $\begin{array}{l}40-49 \\
50-59 \\
40-60 \\
>60 \\
60-69 \\
70-79 \\
\geqslant 70\end{array}$ & $\begin{array}{l}3 / 5 \\
7 / 8 \\
10 / 13 \\
\text { NA } \\
7 / 19 \\
\text { NA } \\
7 / 63\end{array}$ & $\begin{array}{l}0 / 5 \\
0 / 8 \\
0 / 13 \\
\text { NA } \\
1 / 19 \\
6 / 46 \S \\
\text { NA }\end{array}$ & $\begin{array}{l}\text { NA } \\
\text { NA } \\
5 / 13 \\
8 / 82 \\
\text { NA } \\
\text { NA } \\
\text { NA }\end{array}$ & & \\
\hline & \multicolumn{2}{|l|}{ DT } & & & \\
\hline & Mantero ef $a l^{18}$ & Klein ef $a P^{4}$ & & & \\
\hline $\begin{array}{c}40-49 \\
50-59 \\
60-69 \\
70-79 \\
>70\end{array}$ & $\begin{array}{l}1 / 5 \\
0 / 8 \\
6 / 20 \\
9 / 48 \S \\
\text { NA }\end{array}$ & $\begin{array}{l}1 / 5 \\
1 / 8 \\
2 / 20 \\
\text { NA } \\
8 / 65\end{array}$ & & & \\
\hline
\end{tabular}

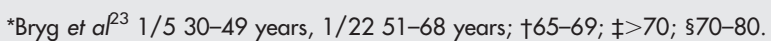

$A$, peak atrial filling; AFF, atrial filling fraction; DT, deceleration time; E, peak rapid filling; IVRT, isovolumetric relaxation time; NA, not available.

Table 3 Concordance between different indices of diastolic dysfunction

\begin{tabular}{|c|c|c|c|c|}
\hline \multirow{2}{*}{$\begin{array}{l}\text { Reference study and patient age range } \\
\text { (years) }\end{array}$} & \multicolumn{4}{|c|}{ Measure of diastolic function } \\
\hline & $\mathrm{E}: \mathrm{A}$ ratio & IVRT & DT & AFF \\
\hline \multicolumn{5}{|l|}{ Mantero et al ${ }^{18}$} \\
\hline $40-49$ & $1 / 5$ & $4 / 5$ & $1 / 5$ & $0 / 5$ \\
\hline $50-59$ & $0 / 8$ & $5 / 8$ & $0 / 8$ & $0 / 8$ \\
\hline $60-69$ & $4 / 19$ & $4 / 20$ & $6 / 20$ & $1 / 19$ \\
\hline 70-79 & $2 / 47$ & $20 / 51$ & $9 / 48$ & $6 / 46$ \\
\hline \multicolumn{5}{|l|}{ Klein et a ${ }^{24}$} \\
\hline $40-49$ & $1 / 5$ & $3 / 5$ & $1 / 5$ & NA \\
\hline $50-59$ & $3 / 8$ & $0 / 8$ & $1 / 8$ & NA \\
\hline $60-69$ & $4 / 19$ & $0 / 20$ & $2 / 20$ & NA \\
\hline$>70$ & $2 / 64$ & $27 / 67$ & $8 / 65$ & NA \\
\hline \multicolumn{5}{|l|}{ Framingham study 20} \\
\hline $40-49$ & $1 / 5$ & NA & NA & $3 / 5$ \\
\hline $50-59$ & $1 / 8$ & NA & NA & $7 / 8$ \\
\hline $60-69$ & $1 / 19$ & NA & NA & $7 / 19$ \\
\hline$\geqslant 70$ & $2 / 64$ & NA & NA & $7 / 63$ \\
\hline \multicolumn{5}{|l|}{ Voutilainen et $a{ }^{21}$} \\
\hline $40-60$ & $0 / 15$ & $2 / 13$ & NA & $5 / 13$ \\
\hline$>60$ & $9 / 81$ & $52 / 87$ & NA & $8 / 82$ \\
\hline \multicolumn{5}{|l|}{ Spirito et a $\left.\right|^{19}$} \\
\hline $30-49$ & $1 / 5$ & $2 / 5$ & $0 / 5$ & NA \\
\hline $50-74$ & $1 / 54$ & $21 / 60$ & $11 / 56$ & NA \\
\hline \multicolumn{5}{|l|}{ Cohen et al ${ }^{9}$} \\
\hline $21-49$ & $0 / 5$ & $4 / 6$ & $1 / 5$ & NA \\
\hline$\geqslant 50$ & $9 / 91$ & $20 / 95$ & $11 / 93$ & NA \\
\hline
\end{tabular}


Table 4 Prevalence of diastolic dysfunction in the overall patient group and subsets at high risk of diastolic dysfunction

\begin{tabular}{|c|c|c|c|c|c|}
\hline \multirow{2}{*}{$\begin{array}{l}\text { Reference study and patient } \\
\text { age range (years) }\end{array}$} & \multicolumn{5}{|c|}{ Prevalence of abnormal diastolic function } \\
\hline & All patients & Hypertension & LVH & Obesity & Ischaemia \\
\hline \multicolumn{6}{|l|}{ Framingham study ${ }^{20} \geqslant 70$} \\
\hline $\mathrm{E}: \mathrm{A}$ & $2 / 64(3.1 \%)$ & $1 / 34(2.9 \%)$ & $1 / 19(5.3 \%)$ & $0 / 18(0 \%)$ & $1 / 26(3.8 \%)$ \\
\hline AFF & $7 / 63(11.1 \%)$ & $2 / 34(5.9 \%)$ & $1 / 18(5.6 \%)$ & $3 / 17(18 \%)$ & $3 / 26(11.5 \%)$ \\
\hline \multicolumn{6}{|l|}{ Mantero et al ${ }^{8} 60-80$} \\
\hline $\mathrm{E}: \mathrm{A}$ & $6 / 66(9.1 \%)$ & $3 / 35(8.6 \%)$ & $2 / 18$ (11\%) & $1 / 22(5 \%)$ & $4 / 30$ (13\%) \\
\hline AFF & $7 / 65(11 \%)$ & $1 / 35(2.9 \%)$ & $1 / 17(5.9 \%)$ & $5 / 21(24 \%)$ & $6 / 34(18 \%)$ \\
\hline IVRT & $24 / 71$ (34\%) & $16 / 38(42 \%)$ & $8 / 20(40 \%)$ & $6 / 24(25 \%)$ & $13 / 33(39 \%)$ \\
\hline DT & $15 / 68(22 \%)$ & $10 / 36(28 \%)$ & $4 / 18(22 \%)$ & $3 / 23(13 \%)$ & $6 / 33(18 \%)$ \\
\hline \multicolumn{6}{|l|}{ Voutilainen et $a^{21}>60$ ) } \\
\hline AFF & $8 / 82(10 \%)$ & $4 / 42(10 \%)$ & $4 / 22(18 \%)$ & $3 / 23(13 \%)$ & $5 / 34(15 \%)$ \\
\hline IVRT & $52 / 87(60 \%)$ & $25 / 45(56 \%)$ & $13 / 25(52 \%)$ & $8 / 26(31 \%)$ & $22 / 36(61 \%)$ \\
\hline \multicolumn{6}{|l|}{ Klein et $a^{R^{4}}>70$} \\
\hline $\mathrm{E}: \mathrm{A}$ & $2 / 64(3.1 \%)$ & $0 / 34(0 \%)$ & $1 / 19(5.3 \%)$ & $0 / 18(0 \%)$ & $0 / 26(0 \%)$ \\
\hline IVRT & $27 / 67(40 \%)$ & $16 / 36(44 \%)$ & $9 / 21(43 \%)$ & $7 / 19(37 \%)$ & $11 / 27(41 \%)$ \\
\hline DT & $8 / 65(12 \%)$ & $7 / 34(21 \%)$ & $1 / 19(53 \%)$ & $2 / 18(11 \%)$ & $3 / 27(11 \%)$ \\
\hline \multicolumn{6}{|l|}{ Cohen et $a^{\beta} \geqslant 50$} \\
\hline $\mathrm{E}: \mathrm{A}$ & $9 / 91(9.9 \%)$ & $4 / 44(9.1 \%)$ & $3 / 25(12 \%)$ & $1 / 28(4 \%)$ & $3 / 34(9 \%)$ \\
\hline IVRT & $20 / 95(21 \%)$ & $10 / 47(21 \%)$ & $6 / 27(22 \%)$ & $6 / 30(19 \%)$ & $8 / 37(22 \%)$ \\
\hline DT & 11/93 (12\%) & $8 / 45(18 \%)$ & $2 / 27(7 \%)$ & $2 / 29(6 \%)$ & $5 / 37(14 \%)$ \\
\hline \multicolumn{6}{|l|}{ Spirito et al $1^{19} 50-74$} \\
\hline $\mathrm{E}: \mathrm{A}$ & $1 / 54(2 \%)$ & $0 / 26(0 \%)$ & $0 / 14(0 \%)$ & $0 / 22(0 \%)$ & $0 / 19(0 \%)$ \\
\hline IVRT & $21 / 60(35 \%)$ & $11 / 28(39 \%)$ & $5 / 15(33 \%)$ & $9 / 24(36 \%)$ & $8 / 22(36 \%)$ \\
\hline DT & $11 / 56(20 \%)$ & $8 / 27(30 \%)$ & $2 / 14(14 \%)$ & $4 / 23(17 \%)$ & $5 / 21(24 \%)$ \\
\hline \multirow{2}{*}{\multicolumn{6}{|c|}{$\begin{array}{l}\text { European Study Group on } \\
\text { Diastolic Heart Failure } 11^{11}>50\end{array}$}} \\
\hline & & & & & \\
\hline IVRT & $45 / 95(47 \%)$ & 18/47 (38\%) & $14 / 27(52 \%)$ & $15 / 30(50 \%)$ & $16 / 37(43 \%)$ \\
\hline $\mathrm{E}: \mathrm{A}+\mathrm{DT}$ & $3 / 91(3 \%)$ & $2 / 45(4 \%)$ & $1 / 25(4 \%)$ & $0 / 29(0 \%)$ & $1 / 35(3 \%)$ \\
\hline
\end{tabular}

We also examined the two more sophisticated criteria advocated by the European Study Group on Diastolic Heart Failure. ${ }^{11}$ Here, the prevalence of diastolic dysfunction in patients $>50$ years of age based on IVRT was 45 of $95(47 \%)$ compared with 3 of 91 (3\%) based on their E:A ratio plus the deceleration time criterion (table 4).

\section{Measures of diastolic function in patient subsets at high risk of diastolic dysfunction}

Table 4 shows the prevalence of diastolic dysfunction within four patient subsets according to the published normal ranges in our reference studies. Those subsets are believed to include patients at high risk of having diastolic dysfunction. This table is meant to compare the ability of individual measures to identify diastolic dysfunction in these high risk subgroups. As can be seen an increased prevalence of diastolic dysfunction was not evident with any measure in any patient subset.

\section{Combination of measures of diastolic function}

Table 5 shows the prevalence of diastolic dysfunction defined as an abnormality of any one of the measures of diastolic function used in the study concerned. While such an approach obviously increased the prevalence of diastolic dysfunction, it did not enhance differentiation between the high risk subsets and the overall patient group.

\section{DISCUSSION}

There is ever growing interest in the concepts of diastolic dysfunction and diastolic heart failure. ${ }^{1-7}$ Though a number of measurements have been proposed (and accepted) as indices of diastolic function, the concordance of these indices has not been examined. We, therefore, set out to examine just how much agreement there really is between the most commonly used echocardiographic measures of diastolic function. Using published reference ranges, we have applied each of these measures to a single cohort of consecutive

Table 5 Prevalence of diastolic dysfunction (any index within reference study) in the overall patient group and subsets at high risk of diastolic dysfunction

\begin{tabular}{|c|c|c|c|c|c|}
\hline \multirow{2}{*}{$\begin{array}{l}\text { Reference study and patient age } \\
\text { range (years) }\end{array}$} & \multicolumn{5}{|c|}{ Prevalence of abnormal diastolic function } \\
\hline & All patients & Hypertension & LVH & Obesity & Ischaemia \\
\hline $\begin{array}{l}\text { Framingham study }{ }^{20}>70 \\
E: A \text { or AFF }\end{array}$ & $8 / 63(13 \%)$ & $3 / 34(9 \%)$ & $2 / 18(11 \%)$ & $3 / 17(18 \%)$ & $4 / 25(16 \%)$ \\
\hline $\begin{array}{l}\text { Mantero et al }\left.\right|^{8} 60-80 \\
\text { E:A or AFF or IVRT or DT } \\
\text { Klein }{ }^{24}>70\end{array}$ & $36 / 65(56 \%)$ & $20 / 35(57 \%)$ & $11 / 17(65 \%)$ & $10 / 21(48 \%)$ & $20 / 30(67 \%)$ \\
\hline $\begin{array}{l}\text { E:A or IVRT or DT } \\
\text { Cohen et } a^{9}>50\end{array}$ & $26 / 63(41 \%)$ & $15 / 34(44 \%)$ & $8 / 19$ (42\%) & $7 / 17$ (41\%) & $10 / 25(40 \%)$ \\
\hline $\begin{array}{l}\text { E:A or IVRT or DT } \\
\text { Spirto et al }\end{array}$ & $25 / 90(28 \%)$ & $22 / 44(50 \%)$ & $7 / 25(28 \%)$ & $5 / 28(18 \%)$ & $16 / 34(47 \%)$ \\
\hline $\begin{array}{l}50-74 \text { E:A or IVRT or DT } \\
\text { European Study Group on } \\
\text { Diastolic Heart Failure } \\
\text { IVRT or E:A+DT }\end{array}$ & $24 / 54(44 \%)$ & $13 / 26(50 \%)$ & $5 / 14(36 \%)$ & $9 / 22(41 \%)$ & $7 / 19$ (37\%) \\
\hline
\end{tabular}


patients referred for echocardiographic investigation of suspected heart failure. ${ }^{18-24}$ We also specifically examined subsets of patients believed to be at high risk of diastolic dysfunction (that is, patients with hypertension, left ventricular hypertrophy, obesity, and myocardial ischaemia). ${ }^{1-7}$ Obviously, if each of these indices is a true measurement of diastolic function then they should generally identify the same patients with abnormal diastolic function. Furthermore, they should each identify a greater proportion of patients at high risk of abnormal diastolic function as having diastolic dysfunction. We found neither of these things. There was very poor concordance between measures with up to a 16-fold difference in prevalence in the overall patient cohort, depending on what measure of diastolic function was used. There was also little difference in the proportion of patients with abnormal diastolic function in the overall cohort and the high risk subsets.

As we have reported previously, even the two recently recommended echocardiographic criteria of the European Study Group on Diastolic Heart Failure give widely discordant prevalences. These criteria do not seem at all discriminating when the high risk patient subsets are examined. ${ }^{11}{ }^{25-27}$ Almost identical findings (and a similar conclusion) have recently been reported by Cahill and colleagues. ${ }^{26}$

What are the implications of these findings? These results suggest that, based on the available reference ranges in the literature, none of the commonly used echocardiographic measures of diastolic function are reliable. They neither agree with each other nor identify patients at high risk of diastolic dysfunction individually.

These conclusions, however, are greatly influenced by one index, the IVRT, which appears to over-diagnose diastolic dysfunction and which may be an invalid measure of diastolic function. ${ }^{28}$

Other indices may be influenced by loading conditions and, therefore, pharmacological treatment. It is important to point out, however, that this is unavoidable in "real world", elderly patients, who often have a number of concomitant medical problems and take a variety of medications. Indeed, these are just the type of breathless patients sent for echocardiographic examination and who are often subsequently labelled as having diastolic dysfunction.

It can also be argued that at least some of these indices quantify slightly different aspects of diastolic function and that all of them should be measured to detect diastolic dysfunction-that is, that an abnormality of any one is sufficient for this diagnosis. ${ }^{28} 29$ This is the conceptual approach recently adopted by Zile and colleagues, ${ }^{29}$ who made invasive haemodynamic and Doppler ultrasound measurements in 63 patients with a clinical diagnosis of heart failure and echocardiographic left ventricular hypertrophy. Of these $63,79 \%$ had an abnormal relaxation time constant and $92 \%$ a left ventricular end diastolic pressure of $>16 \mathrm{~mm} \mathrm{Hg}$ (both taken as haemodynamic yardstick diagnostic criteria for diastolic dysfunction). Zile and colleagues then calculated the proportions of patients with a variety of Doppler measures of diastolic function outside their "normal" range. These were 38\% for IVRT, 48\% for E:A ratio, and $64 \%$ for deceleration time; at least one index was abnormal in $94 \%$ of patients. We also examined this approach and found that, in the subset of patients with left ventricular hypertrophy, up to $65 \%$ (range $11-65 \%$, mean $39 \%$ ) of our patients had diastolic dysfunction, depending on the criteria used. Our criteria for defining "abnormal" (>2 standard deviations outside the upper and lower limits of age and sex specific normal ranges) were, however, more stringent than those of Zile and colleagues ${ }^{29}$ and this may, at least in part, account for the lower abnormal proportion of patients in our study. Our patients also had a primary care rather than secondary care diagnosis of heart failure and probably had a less advanced condition than those studied by Zile and colleagues. ${ }^{29}$ Whether this approach is a valid one, however, is open to question. If, as Brutsaer ${ }^{28}$ has argued so cogently, IVRT is not a valid Doppler measure of diastolic function, then our conclusion about the prevalence of diastolic dysfunction, using the approach of Zile and colleagues, ${ }^{29}$ would have to be revised (as, almost certainly, would the conclusion of these other authors).

Clearly, there are invasive haemodynamic, nuclear, and magnetic resonance measures of diastolic function, as well as newer echocardiographic ones that may be reliable. ${ }^{13}{ }^{30-34}$ The purpose of this study was, however, to test the validity of those most commonly used at present and advocated by expert groups. The other measures are not in general use and most remain research tools. One group has attempted to validate a complex combination of Doppler techniques: mitral inflow (before and at peak Valsalva), Doppler tissue imaging of mitral annular imaging, and pulmonary venous flow. ${ }^{34} 35$ Unfortunately, even in the population studied (all were referred for evaluation of either angina or heart failure), the predictive accuracy of any of these indices alone or in combination was suboptimal. This group subsequently used these same Doppler measures in a sample of the general population. ${ }^{35}$ In that study, almost $30 \%$ of the general population were felt to have diastolic dysfunction. ${ }^{35}$ Interestingly, in another population based study in Germany, which used the European Study Group echocardiographic criteria, only $11.1 \%$ were found to have diastolic abnormalities. ${ }^{27}$ We believe that these Doppler techniques require further validation in appropriate populations before diastolic abnormalities are diagnosed.

Though it can be argued that our group of patients was relatively small, it did represent a reasonably large, consecutive series of patients with suspected heart failure and a high prevalence of hypertension and coronary heart diseaseexactly the patient group where a diagnosis of diastolic heart failure is often inferred. Our findings challenge the use of this diagnosis based on echocardiographic criteria, especially as this group of patients typically has a number of other potential explanations for their symptoms (obesity, pulmonary disease, myocardial ischaemia) amenable to specific management. ${ }^{15}$ Physicians should be cautious about echocardiographic reports describing diastolic dysfunction and only apply the diagnosis of diastolic heart failure with great care, after thorough assessment to evaluate other possible diagnoses. ${ }^{12}{ }^{15}$ Even then, a diagnosis of "heart failure with preserved left ventricular systolic function" or "preserved left ventricular ejection fraction heart failure" may be more accurate, if less succinct.

\section{Authors' affiliations \\ M C Petrie, K Hogg, L Caruana, J J V McMurray, Department of Cardiology, Western Infirmary, Glasgow, UK}

\section{REFERENCES}

1 Zile MR, Brutsaert DL. New concepts in diastolic dysfunction and diastolic heart failure. Part I. Diagnosis, prognosis, and measurements of diastolic function. Circulation 2002;105:1387-93.

2 Zile MR, Brutsaert DL. New concepts in diastolic dysfunction and diastolic heart failure. Part II. Causal mechanisms and treatment. Circulation 2002; 105:1503-8.

3 Vasan RS, Benjamin EJ, Levy D. Prevalence, clinical features and prognosis of diastolic heart failure: an epidemiologic perspective. J Am Coll Cardiol 1995;26:1565-74

4 Senni M, Tribouilloy C, Rodeheffer RJ, et al. Congestive heart failure in the community: a study of all incident cases in Olmsted County, Minnesota, in 1991. Circulation 1998:98:2282-9. 
5 Vasan RS, Benjamin EJ. Diastolic heart failure: no time to relax. N Engl J Med 2001;344:56-9.

6 Petrie M, McMurray J. Changes in notions about heart failure. Lancet 2001;358:432-4.

7 Chen HH, Lainchbury JG, Senni M, et al. Diastolic heart failure in the community: clinical profile, natural history, therapy and impact of proposed diagnostic criteria. J Card Fail 2002;8:279-87.

8 Taylor R, Waggoner AD. Doppler assessment of left ventricular diastolic dysfunction: a review. J Am Soc Echocardiogr 1992;5:603-12.

9 Cohen GI, Pietrolungo JF, Thomas JD, et al. A practical guide to assessment of ventricular diastolic function using Doppler echocardiography. J Am Coll Cardiol 1996;27:1753-60.

10 Oh JK, Appleton CP, Hatle LK, et al. The noninvasive assessment of left ventricular diastolic function with two-dimensional and Doppler echocardiography. J Am Soc Echocardiogr 1997; 10:246-70.

11 European Study Group on Diastolic Heart Failure. How to diagnose diastolic heart failure. Eur Heart J 1998;19:990-1003.

12 Vasan RS, Levy D. Defining diastolic heart failure: a call for standardized diagnostic criteria. Circulation 2000;101:2118-21.

13 Rakowski H, Appleton C, Chan KL, et al. Canadian consensus recommendations for the measurement and reporting of diastolic dysfunction by echocardiography: from the Investigators of Consensus on Diastolic Dysfunction by Echocardiography. J Am Soc Echocardiogr 1996:9:736-60.

14 Petrie MC, Caruana L, Berry C, et al. "Diastolic heart failure" or heart failure caused by subtle left ventricular systolic dysfunction? Heart 2002;87:29-31.

15 Caruana L, Petrie MC, Davie AP, et al. Do patients with suspected heart failure and preserved left ventricular systolic function suffer from "diastolic heart failure" or from misdiagnosis? A prospective descriptive study. BMJ 2000;321:215-8.

16 Choy AM, Darbar D, Lang CC, et al. Detection of left ventricular dysfunction after acute myocardial infarction: comparison of clinical, echocardiographic, and neurohumoral methods. Br Heart J 1994;72:16-22

17 Willenheimer RB, Israelsson BA, Cline CMJ, et al. Simplified echocardiography in the diagnosis of heart failure. Scand Cardiovasc J 1997;31:9-16.

18 Mantero A, Gentile F, Gualtierotti C, et al. Left-ventricular diastolic parameters in 288 normal subjects from 20 to 80 years old. Eur Heart J 1995; 16:94-105.

19 Spirito $\mathrm{P}$, Maron BJ. Influence of aging on Doppler echocardiographic indexes of left-ventricular diastolic function. Br Heart J 1988;59:672-9

20 Galderisi M, Benjamin EJ, Evans JC, et al. Intraobserver and interobserver reproducibility of Doppler-assessed indexes of left-ventricular diastolic function in a population-based study (the Framingham heart study). Am J Cardiol 1992;70:1341-6.

21 Voutilainen S, Kupari M, Hippelainen M, et al. Factors influencing Doppler indexes of left ventricular filling in healthy persons. Am J Cardiol $1991 ; 68: 653-9$

22 Gardin JM, Arnold AM, Bild DE, et al. Left ventricular diastolic filling in the elderly: The cardiovascular health study. Am J Cardiol 1998;82:345-51.

23 Bryg RJ, Williams GA, Labovitz AJ. Effect of aging on left-ventricular diastolic filling in normal subjects. Am J Cardiol 1987;59:971-4.

24 Klein AL, Burstow DJ, Tajik AJ, et al. Effects of age on left ventricular dimensions and filling dynamics in 117 normal persons. Mayo Clin Proc 1994;69:212-24.

25 Caruana L, Davie AP, Petrie M, et al. Diagnosing heart failure. Eur Heart J $1999 ; 20: 393$.

26 Cahill JM, Horan M, Quigley $P$, et al. Doppler-echocardiographic indices of diastolic function in heart failure admissions with preserved left ventricular systolic function. Eur J Heart Fail 2002;4:473-8.

27 Fischer M, Baessler A, Hense HW, et al. Prevalence of left ventricular diastolic dysfunction in the community. Eur Heart J 2003;24:320-8.

28 Brutsaert DL. Diagnosing primary diastolic heart failure. Eur Heart J 2000;21:94-6.

29 Zile MR, Gaasch WH, Carroll JD, et al. Heart failure with a normal ejection fraction: is measurement of diastolic function necessary to make the diagnosis of diastolic heart failure? Circulation 2001; 104:779-82.

30 Farias CA, Rodriguez L, Garcia M, et al. Assessment of diastolic function by tissue Doppler echocardiography: comparison with standard transmitral and pulmonary venous flow. J Am Soc Echocardiogr 1999; 12:609-17.

31 Appleton CP, Firstenberg MS, Garcia MJ, et al. The echo-Doppler evaluation of left ventricular diastolic function. A current perspective. Cardiol Clin 2000;3:513-46.

32 van Kraaij DJ, van Pol PE, Ruiters AW, et al. Diagnosing diastolic heart failure. Eur J Heart Fail 2002:4:419-30.

33 Paelinck BP, Lamb HJ, Bax JJ, et al. Assessment of diastolic function by cardiovascular magnetic resonance. Am Heart J 2002;144:198-205.

34 Ommen SR, Nishimura RA, Appleton CP, et al. Clinical utility of Doppler echocardiography and tissue Doppler imaging in the estimation of left ventricular filling pressures: a comparative simultaneous Doppler catheterisation study. Circulation 2000; 102:1788-94.

35 Redfield MM, Jacobsen SJ, Burnett JC Jr, et al. Burden of systolic and diastolic ventricular dysfunction in the community. JAMA 2003;289:194-202.

\section{APPENDIX 1: DOPPLER ECHOCARDIOGRAPHY NORMAL RANGES CALCULATED FROM REFERENCE STUDIES}

\begin{tabular}{|c|c|c|c|c|c|c|}
\hline Study & Age range (years) & E:A ratio & IVRT & DT & AfF & $E: A+D T$ \\
\hline \multicolumn{7}{|c|}{ Framingham study ${ }^{20}(n=127)$} \\
\hline & $20-29$ & $0.98-3.18$ & & & $0.14-0.34$ & \\
\hline & 30-39 & $0.95-2.55$ & & & $0.15-0.35$ & \\
\hline & $40-49$ & $0.92-1.96$ & & & $0.23-0.35$ & \\
\hline & $50-59$ & $0.73-1.85$ & & & $0.22-0.38$ & \\
\hline & $60-69$ & $0.51-1.55$ & & & $0.23-0.47$ & \\
\hline & $\geqslant 70$ & $0.26-1.42$ & & & $0.24-0.60$ & \\
\hline & All ages & $0.32-2.48$ & & & $0.15-0.47$ & \\
\hline \multicolumn{7}{|c|}{ Cardiovascular health study $y^{22}(\mathrm{n}=980)$} \\
\hline \multirow{2}{*}{\multicolumn{7}{|c|}{ Women }} \\
\hline & & & & & & \\
\hline & $65-69$ & $0.50-1.62$ & & & & \\
\hline & $70-74$ & $0.50-1.42$ & & & & \\
\hline & 75-79 & $0.52-1.28$ & & & & \\
\hline & $>80$ & $0.48-1.12$ & & & & \\
\hline \multicolumn{7}{|c|}{ Men } \\
\hline & $65-69$ & $0.52-1.64$ & & & & \\
\hline & $70-74$ & $0.44-1.48$ & & & & \\
\hline & 75-79 & $0.47-1.39$ & & & & \\
\hline & $>80$ & $0.48-1.16$ & & & & \\
\hline \multicolumn{7}{|c|}{ Mantero $^{18}(\mathrm{n}=288)$} \\
\hline & $20-29$ & $0.9-2.9$ & $41.2-94.8$ & $97.2-194.4$ & $0.04-0.44$ & \\
\hline & $30-39$ & $0.9-2.5$ & $45.3-97.7$ & $94.2-283.8$ & $0.07-0.47$ & \\
\hline & $40-49$ & $0.8-2.0$ & $49.0-97.8$ & $93.2-218.8$ & $0.10-0.50$ & \\
\hline & $50-59$ & $0.6-1.8$ & $51.7-102.9$ & $87.5-222.3$ & $0.14-0.54$ & \\
\hline & $60-69$ & $0.6-1.4$ & $51.0-107.8$ & $103.5-241.1$ & $0.17-0.57$ & \\
\hline & $70-80$ & $0.2-1.4$ & $44.7-117.5$ & $86.5-269.7$ & $0.19-0.59$ & \\
\hline \multicolumn{7}{|c|}{ Voutilainen $^{21}(\mathrm{n}=93)$} \\
\hline & $<40$ & $1.0-3.0$ & $101-177$ & & $0.11-0.35$ & \\
\hline & $40-60$ & $0.6-1.8$ & 100-204 & & $0.20-0.48$ & \\
\hline & $>60$ & $0.76-0.84$ & $112-216$ & & $0.27-0.63$ & \\
\hline & All & $0.3-2.7$ & $99-199$ & & $0.08-0.56$ & \\
\hline
\end{tabular}




\begin{tabular}{|c|c|c|c|c|c|c|}
\hline Study & Age range (years) & E:A ratio & IVRT & DT & AfF & $E: A+D T$ \\
\hline \multicolumn{7}{|c|}{ Klein $^{24}(n=117)$} \\
\hline & $<50$ & $0.7-3.1$ & $54-98$ & $139-219$ & & \\
\hline & $>50$ & $0.5-1.7$ & $56-124$ & $138-282$ & & \\
\hline & $20-29$ & $0.8-3.6$ & $49-93$ & $144-220$ & & \\
\hline & $30-39$ & $0.9-2.5$ & $63-95$ & $138-214$ & & \\
\hline & $40-49$ & $0.8-2.4$ & 53-105 & $131-223$ & & \\
\hline & $50-59$ & $0.9-1.7$ & $52-124$ & $157-245$ & & \\
\hline & $60-69$ & $0.6-1.4$ & $60-128$ & $132-296$ & & \\
\hline & $>70$ & $0.2-1.8$ & $56-116$ & $135-303$ & & \\
\hline \multicolumn{7}{|c|}{ European Study Group on Diastolic Heart Failure ${ }^{11}$ (review) } \\
\hline & & & Age $<30$ & & & Age $<50$ \\
\hline & & & IVRT >92 & & & $E: A<1.0$ \\
\hline & & & Age $30-50$ & & & $\mathrm{DT}>220$ \\
\hline & & & IVRT $>100$ & & & Age $>50$ \\
\hline & & & Age $>50$ & & & $\mathrm{E}: \mathrm{A}<0.5$ \\
\hline & & & IVRT >105 & & & DT $>280$ \\
\hline \multicolumn{7}{|c|}{ Cohen $^{9}(\mathrm{n}=107)$} \\
\hline & $21-49$ & $1.9\left(0.7-3.1^{*}\right)$ & $76\left(54-98^{*}\right)$ & $179\left(139-219^{*}\right)$ & & \\
\hline & $\geqslant 50$ & $1.1\left(0.5-1.7^{*}\right)$ & $90\left(56-124^{*}\right)$ & $210\left(138-282^{*}\right)$ & & \\
\hline \multicolumn{7}{|c|}{$\operatorname{Bryg}^{23}(n=32)$} \\
\hline & $24-29$ & $0.92-3.04$ & & & & \\
\hline & $30-49$ & $0.80-2.24$ & & & & \\
\hline & $51-68$ & $0.25-1.89$ & & & & \\
\hline \multicolumn{7}{|c|}{ Spirito $^{19}(n=86)$} \\
\hline & $20-29$ & $1.3-4.1$ & $48-96$ & $158-278$ & & \\
\hline & $30-49$ & $0.8-3.2$ & $56-104$ & $166-274$ & & \\
\hline & $50-74$ & $0.4-2.0$ & $60-108$ & $155-287$ & & \\
\hline
\end{tabular}

\section{ELECTRONIC PAGES}

\section{Heart Online case reports: www.heartjnl.com}

$\mathrm{T}$

he follow electronic only articles are published in conjunction with this issue of Heart.

Vasovagal syncope interrupting sleep?

C T P Krediet, D L Jardine, P Cortelli, A G R Visman, W Wieling

Clinical data are reported for 13 patients who were referred with recurrent loss of consciousness at night interrupting their sleep. Most of the patients were women (10 of 13) with a mean age of 45 years (range 21-72 years). The histories were more consistent with vasovagal syncope than with epilepsy. This was supported by electroencephalographic and tilt test results. More polysomnographic monitoring data are required to confirm the diagnosis of vasovagal syncope interrupting sleep. This will be difficult because, although the condition may not be rare, the episodes are usually sporadic.
(Heart 2004;90:e25) www.heartjnl.com/cgi/content/full/90/ $5 / \mathrm{e} 25$

Acute myocardial infarction caused by thrombotic occlusion at a stent site two years after conventional stent implantation

T Hayashi, A Kimura, K Ishikawa

Two cases of acute myocardial infarction caused by thrombotic occlusion at the conventional stented site two years after stenting are described. Late thrombotic stent occlusion may be caused by atherosclerotic regression, sustained inflammatory reaction, and inhibition of proliferation of neointima. Cardiologists must be aware of the potential for late thrombosis following even conventional stent implantation.

(Heart 2004;90:e26) www.heartjnl.com/cgi/content/full/90/ $5 / \mathrm{e} 26$ 